Solubility of Strontium-substituted Apatite by Solid Titration

\title{
Pan $\mathrm{HB}^{1,2}$, Li ZY ${ }^{1}$, Lam WM ${ }^{1}$, Wong $\mathrm{JC}^{1}$, Darvell BW ${ }^{2}$, Luk KDK, Lu WW*1 \\ ${ }^{1}$ Department of Orthopaedics \& Traumatology, The University of Hong Kong \\ ${ }^{2}$ Dental Materials Science Unit, The University of Hong Kong
}

* Corresponding author

Lu WW

Department of Orthopaedics \& Traumatology

The University of Hong Kong

21 Sassoon Rd

Hong Kong

Tel: (852) 28185210

Fax: (852) 97381980

Email: wwlu@hkusua.hku.hk 


\begin{abstract}
Solid titration was used to explore the solubility isotherms of partially- (Srx-HAp, $\mathrm{x}=1,5,10,40$, $60 \mathrm{~mole} \%$ ) and fully-substituted strontium hydroxyapatite (Sr-HAp). Solubility increased with increase of strontium content. No other phase than Sr-substituted HAp, corresponding to the original titrant was detected in the solid present at equilibrium; in particular DCPD was not detected at low $\mathrm{pH}$. The increase of solubility with $\mathrm{Sr}$ content is interpreted as a destabilization of the crystal structure by the larger strontium ion. Carbonated HAp was formed in simulated body fluid (SBF) containing carbonate on seeding with Sr10-HAp, but the precipitate was strontium-substituted on seeding with Sr-HAp. Strontium-substituted HAp might be usable as a template for the growth of new bone, since nucleation appears to be facilitated.
\end{abstract}

Key words: Solid titration, Solubility, Strontium-substituted Apatite, Hydroxyapatite 


\section{Introduction}

Hydroxyapatite (HAp), $\mathrm{Ca}_{5}\left(\mathrm{PO}_{4}\right)_{3} \mathrm{OH}$, is the principal parent mineral of bone and tooth tissue. However, it is never found in a pure form in nature since substitution occurs readily by other elements such as sodium, magnesium, carbonate and fluoride; such substitutions can occur at all three site types: calcium, phosphate and hydroxide. In particular, strontium may substitute at $\mathrm{Ca}$ sites, forming a continuous solid solution (Srx-HAp) up to full substitution (Sr-HAp) due to chemical similarity. Strontium is believed to play an important role in the treatment of osteoporosis and enhancement of bone remineralization as it is associated with a reduction of bone resorption, an increase in the formation of new bone, and a decrease in the risk of bone fracture [1]. Consequently, a number of strontium-containing materials have been extensively used as a bone filler, such as partially strontium-substituted HAp [2-5], $\alpha$-TCP [6], and $\mathrm{CaSiO}_{3}$ [7], as well as strontium-containing cement $[8,9]$. In addition, strontium-containing toothpaste was developed to enhance the remineralization of dental enamel [10], and recently drugs such as strontium ranelate (SrR) [11] have been suggested for use as a daily supplement to increase bone mineral density.

However, the mechanism and behaviour of strontium in such systems are controversial. Grynpas [12] thought that the incorporation of strontium induced hypomineralization by weakening the apatite lattice and so increasing bone mineral solubility, while it was recently reported that no stimulation of new bone formation was found in ovariectomized rats after SrR intake for three months [13]. On the other hand, Christoffersen et al. [14] and Dedhiya et al. [15] found that strontium significantly inhibited the dissolution of HAp, and a "surface complex", $\mathrm{Ca}_{3} \mathrm{Sr}_{2}\left(\mathrm{PO}_{4}\right)_{3} \mathrm{OH}$ (40\% Sr-substituted HAp, Sr40-HAp) has been postulated to account for such dissolution retardation [16]. But as indicated by Christoffersen et al. [14] themselves, the solubility of strontium-substituted apatite increases with the increase of strontium content. The question therefore arises of how a more soluble phase could cover a more stable phase spontaneously at equilibrium? A thorough check of the effect of strontium on its solubility is necessary. 
One immediate concern is that the incongruent dissolution of HAp [17-19] has been known since at least the 1930s: the apparent solubility increases with increase of the amount of solid present. The conclusion of Levinskas and Neuman [20] that no solubility product (SP) for HAp can be calculated can be attributed to this. In fact, although a number of dissolution models have been discussed before [19], consideration of the method itself is usually neglected. For calcium phosphates, difficulties arise from the formation of intermediate phases such as dicalcium hydrogen phosphate (DCPD), octacalcium phosphate (OCP) and amorphous calcium phosphate (ACP), which have been reported to nucleate more easily, which lead to shifts in solution equlibria. Crucially, however, seldom has the attempt been made to analyse the composition and phase constitution of the solid at equilibrium as it has been assumed that no phase transformation occurs (HAp is reported as the most stable phase at $\mathrm{pH}>4.2$ [21]), despite the solution $\mathrm{Ca} / \mathrm{P}$ ratio varying greatly. Problems are commonly ascribed to the formation of complexes [19, 22, 23]. Any such determined solubility does not correspond to the original solid, and lacks both precision and accuracy. Furthermore, the calculation of a solubility product (SP) requires knowledge of all relevant equilibria, but the presence of a dozen or so equilibria has been neglected or ignored, such as for $\mathrm{CaH}_{2} \mathrm{PO}_{4}{ }^{+}, \mathrm{CaPO}_{4}{ }^{-}$ [24]. Such simplification is an unwarranted and crude approximation; such calculated SPs are therefore meaningless.

Recognizing these difficulties, the solid titration approach for determining mass solubility was developed $[25,26]$. In this, a series of only very small increments of the relevant solid are added to the test solution as the end-point is approached, with the end-point of remnant solid (or new precipitate) being detected by a low-angle laser-scattering system; the system depends on the complete dissolution of each increment before the next is added. Thus, although the dissolution of the solid itself may still be incongruent whilst there is solid present, at the end-point the excess solid is vanishingly small, thus avoiding both the appreciable supersaturation and uncertain solution composition which arise from a large excess of solid. Using this technique, HAp has been 
confirmed to be substantially less soluble than previously reported [26]. In particular, DCPD has been found not to be the most stable phase at low $\mathrm{pH}$ as hitherto believed, rather, it is a calcium-deficient HAp which is. Meanwhile, the reliability and reproducibility of solid-titration has been confirmed for a relatively simple system, $\mathrm{CaF}_{2}$ [27], with the experimental solubility isotherm consistent with the theoretical result over a wide $\mathrm{pH}$ range and other reports [28, 29]. Therefore, solid titration may be the only viable approach to explore true solution equilibria for complicated systems such as the calcium phosphates. The extension to other systems is natural, and in particular the effect of strontium is of special interest here, where the debate might arise from failure to understand the true solution equilibria.

However, the literature contains little in the way of solubility data of for Srx-HAp [30]. Thus, in the present context determination of the true solubility of Sr-containing apatites is both necessary and urgent. The aim of the present work was therefore to determine the solid titration curves for Srx-HAp, with the composition of the precipitate at equilibrium needing to be determined in order to ascertain whether such curves represent solubility isotherms for the titrant solid composition. In addition, seeding of these solids in simulated body fluid (SBF) solution might be helpful to understand the effect of strontium in vivo.

\section{Materials and Methods}

\subsection{Titrant preparation}

Strontium-substituted apatite, Srx-HAp $[\mathrm{x}=\mathrm{Sr} /(\mathrm{Ca}+\mathrm{Sr})=1,5,10,4060 \mathrm{~mole} \%]$ and fully-substituted strontium apatite (Sr-HAp) were synthesized using an hydrothermal method at $150{ }^{\circ} \mathrm{C}$ for $14 \mathrm{~h}$ by adding $\left(\mathrm{NH}_{4}\right)_{2} \mathrm{HPO}_{4}$ solution (analytical grade, Merck, Darmstadt, Germany) into a solution of $\mathrm{Sr}\left(\mathrm{NO}_{3}\right)_{2}$ and $\mathrm{Ca}\left(\mathrm{NO}_{3}\right)_{2}$ in the corresponding molar ratio (both analytical grade, $\mathrm{BDH}$, Poole, England), with the product $(\mathrm{Ca}+\mathrm{Sr}) / \mathrm{P}$ ratio 1.67 (stoichiometric for apatites) as previously described [31]. Ammonium hydroxide solution (Aristar, BDH) was used to adjust to 
initial $\mathrm{pH}$ 10. The precipitate was washed several times each with deionized water and absolute ethanol, and finally dried at $90{ }^{\circ} \mathrm{C}$ overnight.

\subsection{Solid titration}

The solubility of each solid Srx-HAp in $600 \mathrm{~mL}$ of $100 \mathrm{mM} \mathrm{KCl}$ solution at $37.0 \pm 0.1{ }^{\circ} \mathrm{C}$ was investigated. The solution was flushed with nitrogen, and all conditions were as previously reported for HAp [26]. The end-point of the titration was determined by a semiconductor-diode laser-scattering system ( $1 \mathrm{~mW} \mathrm{CW,} \mathrm{194-010,} \mathrm{RS} \mathrm{Components,} \mathrm{UK).} \mathrm{The} \mathrm{intensity} \mathrm{of} \mathrm{the} \mathrm{initial}$ signal was approximately proportional to the amount of added solid. Each addition of the solid, even if less than $0.5 \mathrm{mg}$, caused an obvious step-increase in the laser-detector output signal. With time, this signal decreased due to the dissolution of the solid. The time taken depended on the particle dissolution rate. When a stable signal was obtained for an hour or more at or very close to the original baseline value, it was taken as indicating that the solid added had completely dissolved; the next solid addition could then be made. Therefore, the end-point of the titration could be unambiguously detected by the output signal remaining higher than the original baseline, indicating that no more solid could dissolve or that a new solid had precipitated, or both. The estimate of the end-point of the titration was refined by interpolation as previously described [26], after a further small increment. The $\mathrm{pH}$ value could then be adjusted to a lower value by adding $\mathrm{HCl}$ (1 M solution, analytical grade, BDH; dropwise) until all solid had dissolved, permitting a further determination.

\subsection{Solid formation}

In some cases, "preparative" solid was obtained by further addition of a milligram or so of the titrant after the end-point had been reached, allowing a further 10 days for reprecipitation and equilibration, including grain growth, so that sufficient material $(\sim 1 \mathrm{mg})$ was available for analysis after centrifugation and rinsing with a drop or two or deionized water. This approach was necessary because the amount of solid present at the end-point was intended to be vanishingly small 
and thus insufficient on its own for characterization.

\subsection{Seeding of titrants in SBF}

Sr10-HAp has been widely studied in vitro and used in vivo, in particular as the main inorganic phase for the preparation of bone cement [32]. Pure, fully-substituted Sr-HAp is also of special interest as the limiting case. These two solids were therefore chosen to study the seeding behaviour in simulated body fluid (SBF), prepared according to Kokubo et al. [33], which solution is metastable, being greatly supersaturated with respect to HAp. In each case, a $1 \mathrm{mg}$ portion of the solid was added into $600 \mathrm{~mL}$ SBF solution at $37.0 \pm 0.1{ }^{\circ} \mathrm{C}$, and allowed to equilibrate for $2 \mathrm{~d}$ (as determined by the laser-scattering signal). A second portion of 2-3 $\mathrm{mg}$ titrant was then added, and allowed to equilibrate for a further $10 \mathrm{~d}$, following which the solid was retrieved by centrifugation, and rinsed with one drop of deionized water.

\subsection{Characterization}

The constitution of the original titrants was characterized by X-ray diffraction (XRD) (Model $\mathrm{D} / \mathrm{max} 2550 \mathrm{~V}$, Rigaku, Tokyo, Japan) using $\mathrm{Cu} \mathrm{K} \alpha(\lambda=1.5406 \AA)$ radiation in step-scan mode (2 $\theta$ $=0.02^{\circ}$ per step). The precipitate was characterized by selected-area electron diffraction (SAED) (Technai G2 20 TEM, FEI, Hillsboro, OR, USA) due to the small amount of 'preparative' solid obtained at equilibrium. Ring radii were calculated in image-analysis software (QWin, Leica Microsystems Imaging Solutions, Cambridge, UK). The composition of titrants and precipitates was determined using EDX (LEO 1530 FESEM, Oxford Instruments, Oxford, UK). Five determinations were made on different areas, and the mean and standard deviation for each element calculated. As carbonate is present in SBF, Fourier Transform Infrared spectroscopy (FT-IR, PerkinElmer, USA) was used on the precipitates from those titrations. The morphology of titrants and precipitates was observed by field-emission scanning TEM. 


\section{Results}

\subsection{Titrant}

The required strontium-substituted apatites were successfully prepared and confirmed to be fully apatitic (Fig. 1); although XRD peaks deviated in line with strontium content compared with HAp (JCPDs, 72-1243), no other phase was detected. The calculated $\mathrm{Sr} /(\mathrm{Ca}+\mathrm{Sr})$ ratios were close to the theoretical values (Table 1$)$, and the $(\mathrm{Ca}+\mathrm{Sr}) / \mathrm{P}$ ratio close to the stoichiometric value, 1.67. Crystals became longer with the increase of strontium content, and in particular for Sr40-HAp and above (Fig. 2).

\subsection{Solubility}

The solubility of Srx-HAp significantly and steadily increased with the increase of strontium content (Fig. 3). A marked change of slope in the titration curve was found for Sr1-HAp at $\mathrm{pH} \sim 4.2$, similar to that seen for HAp itself at $\sim$ pH 3.9 [26], but this feature appears to move steadily to higher $\mathrm{pH}$ with increase in strontium content. No other phase was found, and no change from an apatitic structure either side of the slope change, and in particular no evidence was found for either DCPD or strontium hydrogen phosphate $\left(\mathrm{SrHPO}_{4}\right)$ (Fig. 4); the $\mathrm{Sr} /(\mathrm{Ca}+\mathrm{Sr})$ ratio of the end-point solid was close to that of the original titrant, but the $(\mathrm{Ca}+\mathrm{Sr}) / \mathrm{P}$ ratio was lower at the lower $\mathrm{pH}$ in each case (Table 2).

\subsection{Seeding of titrants in SBF}

The addition of $1 \mathrm{mg}$ titrant of both Sr10-HAp and Sr-HAp into SBF solution caused an appreciable increase in the laser output signal over the first day, above the initial step increase, with no return towards the original baseline. No strontium was detected in the precipitate resulting from the addition Sr10-HAp (Table 3); the phase was only identified as 'pure' HAp (Fig. 5). Likewise, calcium was detected in the precipitate resulting from the addition Sr-HAp (Table 3). In addition, carbonate was detected in each case (Fig. 6). 


\section{Discussion}

\subsection{Method}

The applicability and usefulness of solid titration has been confirmed for Srx-HAp. No procedural problems were encountered, and the end-point determination was as clear and unambiguous as for work on other calcium phosphates [34] and calcium fluoride [27]. Similarly long dissolution and equilibration times were required, as might be expected for a closely-related system. The absolute nature of the mass solubility results so obtained lends confidence to the reliability of the results. The reproducibility of the technique may be judged from the low scatter of the points about the trend line in each series.

\subsection{Titrants}

The preparation of the various Srx-HAps, using a method similar to that used for pure HAp [35], relying only the change of solution composition to the required strontium proportion, was effective. EDX showed that the $\mathrm{Sr} /(\mathrm{Ca}+\mathrm{Sr})$ ratio was close to the theoretical and intended values, confirming the chemical homology and solid-solution nature of the system (Table 1), although the congruency implies that calcium is slightly favoured. The ionic radius of strontium (113 pm) is appreciably larger than that of calcium (99 pm), which might be thought tend to destabilize the lattice, but the crystal size (Fig. 2) was found to be larger with the increase of strontium content, and the whisker-like shape observed for Sr-HAp suggest that the increase of ionic radius favours preferential growth in one axis.

\subsection{Solubility}

The solubility of Srx-HAp increased steadily with $\mathrm{x}$, indicating that the Sr does destabilize the structure with respect to solubility, even though Sr-HAp itself is expected to be as ordered as HAp. In fact, the solubility is much higher than that of pure HAp, even for Sr1-HAp (Fig. 3). The marked change of slope was found in all solubility isotherms, but shifted to higher $\mathrm{pH}$. Such a change of 
slope was also found in previous work on HAp [26] and attributed to the onset of formation of calcium-deficient HAp (on the low pH side). That the slope-change occurred at progressively higher $\mathrm{pH}$ implies an ion-size effect. It is noteworthy that no other phase was detected, and especially not DCPD, widely reported to be the most stable phase at $\mathrm{pH}<4.2$ [21]. This is consistent with previous results [26] showing only HAp in the low $\mathrm{pH}$ region. It has to be concluded that the true solution equilibria for strontium apatite has never been obtained by the conventional method through the addition of a large excess of solid to a solution; phase transformations in particular are suspected.

For comparison, the limited data from Verbeeck et al. [30] for Sr10-HAp give a solubility isotherm parallel to, but substantially higher than the present results (Fig. 7). Again, this demonstrates the difficulties of the large excess of solid approach, and the great supersaturation that this causes, with the likelihood of phase transformations. They presented no XRD or other data to support the notion of an equilibrated system with known solid.

In passing, it may be noted that the particle size of the titrant is not of concern, that is, with respect to the surface energy-driven increased solubility of small particles. All titrant is in fact expected to be dissolved unless, as the end-point is exceeded, that solid corresponds exactly to the stable phase. Solid present after the end-point has been passed is newly-nucleated (heterogeneously on titrant) and grown under the conditions of minute supersaturation intended for the method.

Heslop et al. [16], on the basis of fitted data, postulated a "surface complex", $\mathrm{Ca}_{3} \mathrm{Sr}_{2}\left(\mathrm{PO}_{4}\right)_{3} \mathrm{OH}$, that was very slightly less soluble that HAp, citing their calculated $\mathrm{pK}$ values (which require a number of assumptions concerning solution speciation), but with no other evidence such as XRD data adduced in support of the proposal. However, the present results show that the Sr-substituted apatites are substantially more soluble than HAp, so that any superficial ion-exchange process or 
precipitation cannot explain such an outcome. 'Retarded' HAp dissolution may thus be a kinetic phenomenon arising for other reasons. A more soluble phase coating a more stable phase at equilibrium cannot be entertained unless both the precipitation of such a phase was driven from extreme supersaturation at high speed, and that such a coating is perfect, impermeable, and cannot itself nucleate the stable phase - for else this would occur spontaneously (Fig. 3).

The effect of strontium on bone formation therefore seems not to be due to the formation of a surface layer retarding the dissolution of HAp, but may instead be due to the stimulation of the growth of osteoblasts [36], as has been widely reported. The contrary results from Cristoffersen et al. [14] and Dedhiya et al. [15] appear to have arisen from the method they used: using a large excess of solid does not permit an accurate description of the solid, and the absence of a full speciation model for the solution renders a solubility calculation invalid. The solubility increase observed now due to $\mathrm{Sr}$ content is consistent with a decrease of crystal stability, and with the results of Grynpas [12].

\subsection{Behaviour in SBF}

The increase in scattering on seeding SBF indicates that either a new precipitate formed, nucleated on but with dissolution of that seed, or that crystal growth occurred on the seed. That HAp was identified as the only phase in the precipitate resulting from seeding with Sr10-HAp, where no strontium was detectable, suggests the former path. Indeed, the formation of nearly Sr-free HAp is expected as the $\mathrm{Sr} /(\mathrm{Ca}+\mathrm{Sr})$ ratio in the $\mathrm{SBF}(2.5 \mathrm{mM} \mathrm{Ca})$ for $3 \mathrm{mg} \mathrm{Sr} 10-\mathrm{HAp}$ total would be about $1.8 \times 10^{-4}$. SAED verified that the precipitate was apatitic. However, for Sr-HAp seeding, EDX showed that precipitate had a $\mathrm{Ca} /(\mathrm{Ca}+\mathrm{Sr})$ ratio of about 0.10 (Table 3$)$, for a solution molar ratio of about $1.8 \times 10^{-3}$, indicating that a higher strontium concentration may lead to the formation of the substituted apatite; this may reflect ease of nucleation rather than solubility as such. 
Such a postulation is consistent with the result in vivo of using strontium-containing materials as bone filler [37], when a significantly higher concentration of strontium was detected in new bone, but seldom in old bone. This was true as well in OCP-like material, which is found in young bone but seldom in mature bone, and considered to be a precursory phase in the bone formation process [38], even though it is much more soluble than 'pure' HAp. Thus, it may be that nucleation of strontium-substituted apatite is easier than (biological) HAp, and this acts as a template for the formation of new bone, even if it is a metastable phase compared with HAp. Hence, new bone growth might be promoted when strontium is released from a filler material.

Biological apatite is in any case a rather impure HAp. Normally described as a carbonate apatite, it is liable to contain many 'foreign' species. Here, FTIR showed an obvious adsorption peak for carbonate, arising from the $4.2 \mathrm{mM} \mathrm{HCO}_{3}^{-}$in the SBF solution. This presence is due to substitution for phosphate, as indicated by the raised $(\mathrm{Ca}+\mathrm{Sr}) / \mathrm{P}$ ratio $(\sim 2.0)$ (Table 3$)$, and this is believed to occur readily in a physiological environment.

In general, solid-titration seems to be the only viable approach for exploring the true solid solution equilibria for complicated systems, and in particular for biological apatite. Its sensitivity and reliability suggest that it may be applied in other similarly challenging contexts. Using this technique, the solubility of strontium-substituted hydroxyapatite has been mapped, while seeding experiments support the idea of strontium-substituted apatite acting as a template for the formation of new bone.

\section{Acknowledgements}

This study was supported by Hong Kong ITF GHP/009/06 and HKRGC (HKU7147/07E). The authors thank Frankie Chan for his assistance in TEM analysis and Guofeng Chen for XRD analysis. 
References:

[1] Buehler J, Chappuis P, Saffar JL, Tsouderos Y, Vignery A. Strontium ranelate inhibits bone resorption while maintaining bone formation in alveolar bone in monkeys (Macaca fascicularis). Bone 2001;29(2):176-9.

[2] Xue WC, Hosick HL, Bandyopadhyay A, Bose S, Ding CX, Luk KDK, Cheung KMC, Lu WW. Preparation and cell-materials interactions of plasma sprayed strontium-containing hydroxyapatite coating. Surf Coat Tech 2007;201(8):4685-93.

[3] Oliveira AL, Reis RL, Li P. Strontium-substituted apatite coating grown on Ti6Al4V substrate through biomimetic synthesis. J Biomed Mater Res B 2007;83B(1):258-65.

[4] Bigi A, Boanini E, Capuccini C, Gazzano M. Strontium-substituted hydroxyapatite nanocrystals. Inorg Chim Acta 2007;360(3):1009-16.

[5] Donazzon B, Dechambre G, Lacout JL. Calcium-strontium hydroxyapatite: hydrothermal preparation. Ann Chim Sci Mater 1998;23:53-6.

[6] Saint-Jean SJ, Camire CL, Nevsten P, Hansen S, Ginebra MP. Study of the reactivity and in vitro bioactivity of Sr-substituted $\alpha$-TCP cements. J Mater Sci-Mater Med 2005; 16(11):993-1001.

[7] Wu CT, Ramaswamy Y, Kwik D, Zreiqat H. The effect of strontium incorporation into $\mathrm{CaSiO}_{3}$ ceramics on their physical and biological properties. Biomaterials 2007;28(21):3171-81.

[8] Ni GX, Chiu KY, Lu WW, Wang Y, Zhang YG, Hao LB, Li ZY, Lam WM, Lu SB, Luk KD $\mathrm{K}$. Strontium-containing hydroxyapatite bioactive bone cement in revision hip arthroplasty Biomaterials 2006;27(24):4348-55.

[9] Guo DG, Xu KW, Zhao XY, Han Y. Development of a strontium-containing hydroxyapatite bone cement. Biomaterials 2005;26(19):4073-83.

[10] Surdacka A, Stopa J, Torlinski L. In Situ effect of strontium toothpaste on artificially decalcified human enamel Biol Trace Elem Res 2007;116:147-53.

[11] Reginster JY. Strontium ranelate in osteoporosis. Curr Pharm Design 2002;8(21):1907-16.

[12] Grynpas M. Age and Disease-Related Changes in the Mineral of Bone. Calcif Tissue Int 1993;53(suppl 1):S57-S64.

[13] Fuchs RK, Allen MR, Condon KW, Reinwald S, Miller LM, McClenathan D, Keck B, Phipps RJ, Burr DB. Strontium ranelate does not stimulate bone formation in ovariectomized rats. Osteoporos Int 2008 (in press).

[14] Christoffersen J, Christoffersen MR, Kolthoff N, Barenholdt O. Effects of strontium ions on growth and dissolution of hydroxyapatite and on bone mineral detection. Bone 1997;20(1): 47-54.

[15] Dedhiya MG, Young F, Higuchi WI. Mechanism for retardation of acid dissolution rate of hydroxyapatite by strontium. J Dent Res 1973;52(5):1097-109.

[16] Heslop DD, Bi Y, Baig AA, Higuchi WI. Metastable equilibrium solubility behavior of 
carbonated apatite in the presence of solution strontium. Calcif Tissue Int 2004;74(1):72-85.

[17] Smith AN, Posner AM, Quirk JP. Incongruent dissolution and surface complexes of hydroxyapatite. J Colloid Interf Sci 1974;48(3):442-9.

[18] Kaufman HW, Kleinberg I. Studies on the incongruent solubility of hydroxyapatite. Calcif Tissue Int 1979;27(2):143-51.

[19] Dorozhkin SV. Surface reactions of apatite dissolution. J Colloid Interf Sci 1997;191(2):489-97.

[20] Levinskas GJ, Neuman WF. The solubility of bone mineral .1. Solubility studies of synthetic hydroxylapatite. J Phys Chem 1955;59(2):164-8.

[21] Brown PW. Phase-relationships in the ternary-system CaO- $\mathrm{P}_{2} \mathrm{O}_{5}-\mathrm{H}_{2} \mathrm{O}$ at $25{ }^{\circ} \mathrm{C}$. $\mathrm{J}$ Am Ceram Soc 1992;75(1):17-22.

[22] Rootare HM, Deitz VR, Carpenter FG. Solubility product phenomena in hydroxyapatite water systems. J Colloid Sci 1962;17(3):179-206.

[23] La Mer VK. The solubility behavior of hydroxyapatite. J Phys Chem 1962;66:973-8.

[24] Chughtai A, Marshall R, Nancollas GH. Complexes in calcium phosphate solutions. J Phys Chem 1968;72(1):208-11.

[25] Chen ZF, Darvell BW, Leung VWH. Hydroxyapatite solubility in simple inorganic solutions. Arch Oral Biol 2004;49(5):359-67.

[26] Pan HB, Darvell BW. Solubility of hydroxyapatite by solid titration at $\mathrm{pH} 3-4$. Arch Oral Biol 2007;52(7):618-24.

[27] Pan HB, Darvell BW. Solubility of calcium fluoride and fluorapatite by solid titration. Arch Oral Biol 2007;52(9):861-8.

[28] McCann HG. The solubility of fluorapatite and its relationship to that of calcium fluoride Arch Oral Biol 1968;13(8):987-1001.

[29] Larsen MJ, Ravnholt G. Dissolution of various calcium-fluoride preparations in inorganic solutions and in stimulated human saliva. Caries Res 1994;28(6):447-54.

[30] Verbeeck RMH, Driessens FCM, Thun HP, Verbeek F. Stability of calcium-strontium hydroxyapatite solid solutions in aqueous at $25{ }^{\circ} \mathrm{C}$. Bull Soc Chim Belg 1981;90(4):409-17.

[31] Li ZY, Lam WM, Yang C, Xu B, Ni GX, Abbah SA, Cheung KMC, Luk KDK, Lu WW. Chemical composition, crystal size and lattice structural changes after incorporation of strontium into biomimetic apatite. Biomaterials 2007;28(7):1452-60.

[32] Ni GX, Lu WW, Chiu KY, Li ZY, Fong DYT, Luk KDK. Strontium-containing hydroxyapatite (Sr-HA) bioactive cement for primary hip replacement: An in vivo study. J Biomed Mater Res B 2006;77B(2):409-15.

[33] Kokubo T, Kushitani H, Sakka S, Kitsugu T, Yamamuro T. Solutions able to reproduce in-vivo surface structure changes in bioactive A-W glass-ceramics. J Biomed Mater Res 1990;24:721-34.

[34] Pan HB. Solubility of calcium phosphates and related oral minerals by solid titration. $\mathrm{PhD}$ thesis, the University of Hong Kong, 2007. 
[35] Ioku K, Yoshimura M, Somiya S. Hydrothermal synthesis of ultrafine hydroxyapatite single crystals. Nippon Kagaku Kaishi 1988; 9:1565-70.

[36] Caverzasio J. Strontium ranelate promotes osteoblastic cell replication through at least two different mechanisms. Bone 2008;42(6):1131-6.

[37] Dahl SG, Allain P, Marie PJ, Mauras Y, Boivin G, Ammann P, Tsouderos Y, Delmas PD, Christiansen C. Incorporation and distribution of strontium in bone. Bone 2001;28(4):446-53.

[38] Chow LC, Eanes ED. Octacalcium phosphate. Basel: Karger; 2001. 
Table 1 Calculated $\mathrm{Sr} /(\mathrm{Ca}+\mathrm{Sr})$ ratio and $(\mathrm{Ca}+\mathrm{Sr}) / \mathrm{P}$ ratio of the prepared strontium-substituted hydroxyapatites, by EDX (mean \pm s.d., $\mathrm{n}=5$ ).

\begin{tabular}{|c|c|c|c|}
\hline $\begin{array}{c}\text { Substitution } / \% \\
\text { (theoretical original titrant) }\end{array}$ & $\begin{array}{c}\mathrm{Sr} /(\mathrm{Ca}+\mathrm{Sr}) \\
/ \%\end{array}$ & $\begin{array}{c}\text { Congruency } \\
/ \%\end{array}$ & $(\mathrm{Ca}+\mathrm{Sr}) / \mathrm{P}$ \\
\hline 1 & $0.92 \pm 0.03$ & 92 & $1.66 \pm 0.05$ \\
\hline 5 & $4.77 \pm 0.06$ & 95 & $1.65 \pm 0.05$ \\
\hline 10 & $9.68 \pm 0.20$ & 97 & $1.66 \pm 0.05$ \\
\hline 40 & $39.90 \pm 0.38$ & 100 & $1.65 \pm 0.05$ \\
\hline 60 & $58.90 \pm 0.40$ & 98 & $1.65 \pm 0.05$ \\
\hline 100 & 100 & - & $1.66 \pm 0.05$ \\
\hline
\end{tabular}


Table 2 Calculated $\mathrm{Sr} /(\mathrm{Ca}+\mathrm{Sr})$ ratio and $(\mathrm{Ca}+\mathrm{Sr}) / \mathrm{P}$ ratio of the precipitates from solid titration at various $\mathrm{pH}$ values, by $\mathrm{EDX}$ (mean \pm s.d., $\mathrm{n}=5$ ).

\begin{tabular}{|c|c|c|c|c|c|c|c|c|}
\hline \begin{tabular}{c} 
Substitution $\begin{array}{c}\text { 1 } \\
\text { ( } \\
\text { theoretical } \\
\text { original } \\
\text { titrant) }\end{array}$ \\
\cline { 2 - 11 }
\end{tabular} & $\%$ & $\mathrm{pH}$ & $\%$ & $\mathrm{pH}$ & $\%$ & $\mathrm{pH}$ & $\%$ & $\mathrm{pH}$ \\
\hline 1 & $0.89 \pm 0.05$ & 3.95 & $0.90 \pm 0.04$ & 4.67 & $1.57 \pm 0.05$ & 3.95 & $1.61 \pm 0.05$ & 4.67 \\
\hline 5 & $4.67 \pm 0.08$ & 4.03 & $4.66 \pm 0.07$ & 4.88 & $1.55 \pm 0.05$ & 4.03 & $1.63 \pm 0.05$ & 4.88 \\
\hline 10 & $9.66 \pm 0.27$ & 4.07 & $9.70 \pm 0.31$ & 4.91 & $1.58 \pm 0.05$ & 4.07 & $1.61 \pm 0.05$ & 4.91 \\
\hline 40 & $39.51 \pm 0.51$ & 4.06 & $39.45 \pm 0.49$ & 4.83 & $1.56 \pm 0.05$ & 4.06 & $1.60 \pm 0.05$ & 4.83 \\
\hline 60 & $58.43 \pm 0.62$ & 4.11 & $58.37 \pm 0.59$ & 4.96 & $1.54 \pm 0.05$ & 4.11 & $1.60 \pm 0.05$ & 4.96 \\
\hline 100 & 100 & 4.27 & 100 & 5.01 & $1.55 \pm 0.05$ & 4.27 & $1.62 \pm 0.05$ & 5.01 \\
\hline
\end{tabular}


Table $3 \mathrm{Sr}, \mathrm{Ca}, \mathrm{P}$ content and calculated $\mathrm{Sr} /(\mathrm{Ca}+\mathrm{Sr})$ and $(\mathrm{Ca}+\mathrm{Sr}) / \mathrm{P}$ ratios of the precipitates from SBF solution, by EDX (mean \pm s.d., $\mathrm{n}=5$ ).

\begin{tabular}{|c|c|c|c|c|c|}
\hline \multirow{2}{*}{ Original solid in SBF } & \multicolumn{3}{|c|}{ Precipitates } & \multirow{2}{*}{$\begin{array}{c}\mathrm{Sr} /(\mathrm{Ca}+\mathrm{Sr}) \\
/ \%\end{array}$} & \multirow{2}{*}{$(\mathrm{Ca}+\mathrm{Sr}) / \mathrm{P}$} \\
\cline { 2 - 4 } & $\mathrm{Sr}$ & $\mathrm{Ca}$ & $\mathrm{P}$ & - & $1.92 \pm 0.05$ \\
\hline Sr10-HAp & 0 & 17.88 & 9.31 & - & \\
\hline Sr-HAp & 14.19 & 1.51 & 7.88 & $90.38 \pm 1.77$ & $1.99 \pm 0.05$ \\
\hline
\end{tabular}


(figure captions)

Fig. 1 XRD pattern of the solids prepared by hydrothermal method; standard XRD patterns of HAp (JCPDS 72-1243) and Sr-HAp (JCPDs 70-1511) for comparison.

Fig. 2 Typical particle morphologies for the Sr-substituted hydroxyapatites.

Fig. 3 Solubility isotherms for Sr-substituted hydroxyapatites; that for HAp included for comparison $^{26}$.

Fig. 4 Typical precipitate morphologies at various solution $\mathrm{pH}$ values and corresponding selected-area electron diffraction (SAED) rings.

Fig. 5 Precipitate morphology for addition of $1 \mathrm{mg}$ Sr10-HAp, and Sr-HAp in SBF solution, and corresponding selected-area electron diffraction (SAED) rings.

Fig. 6 Fourier-transform infrared spectra of precipitates from SBF solution; those of original added solids shown for comparison.

Fig. 7 Comparison of solubility results for Sr10-HAp by excess-solid (open symbols) and solid titration (solid symbols). 
Pan et al.

Fig. 1

\section{Intensity}

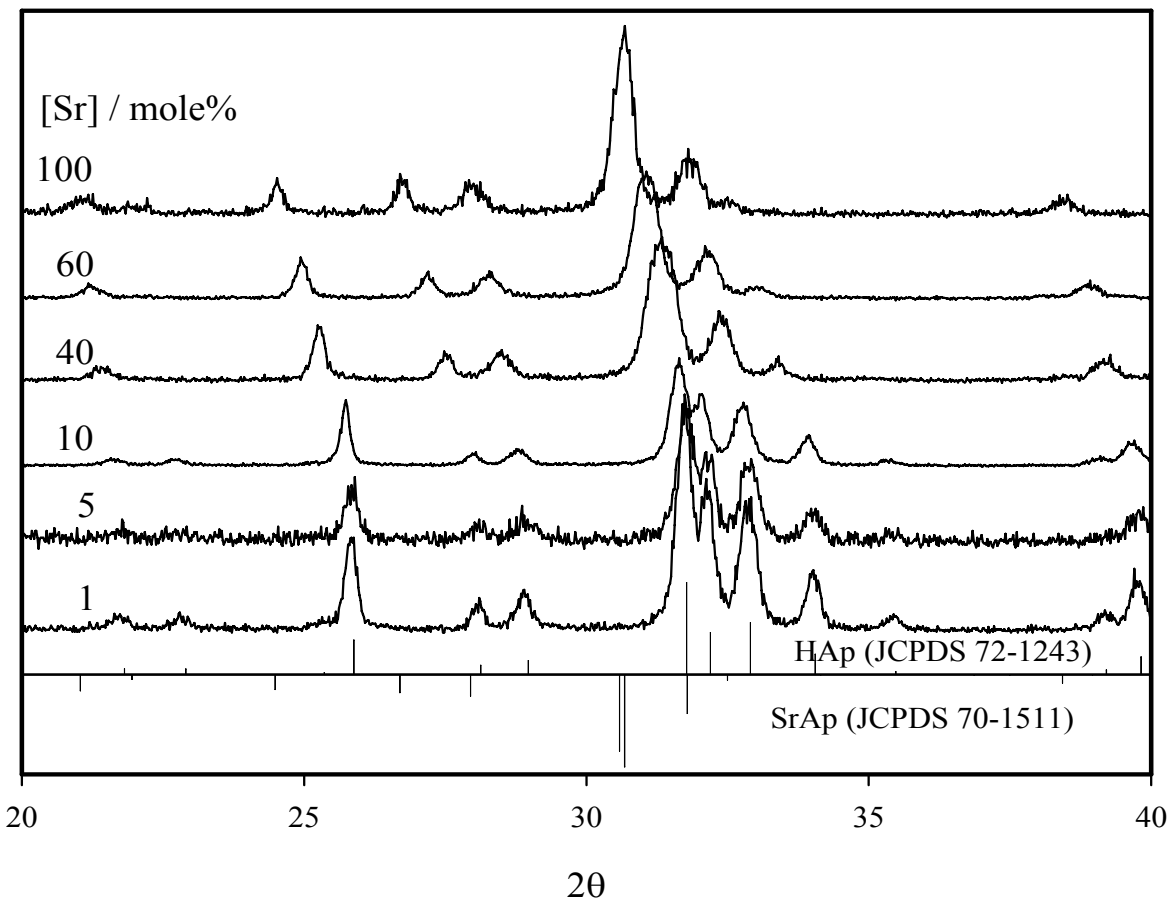


Pan et al.

Fig. 2

\section{Sr1-HAp}

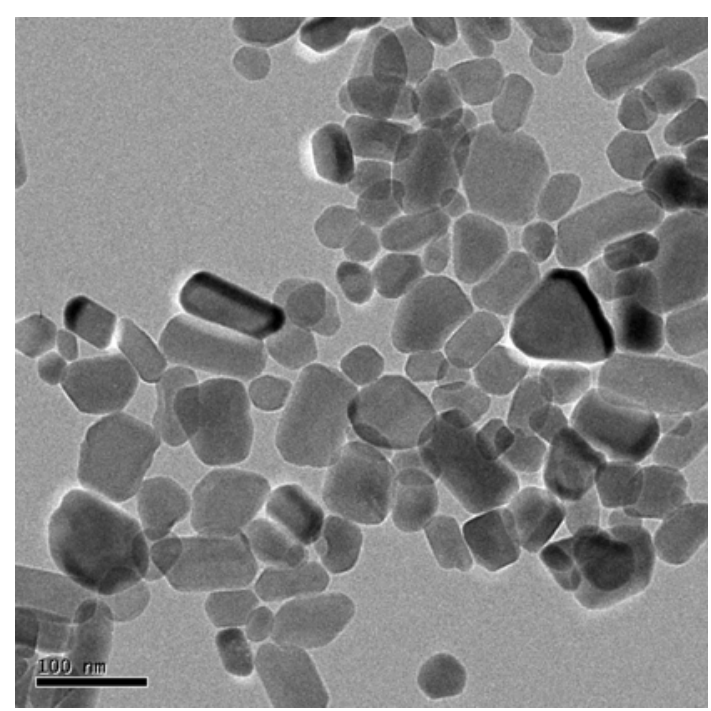

Sr40-HAp

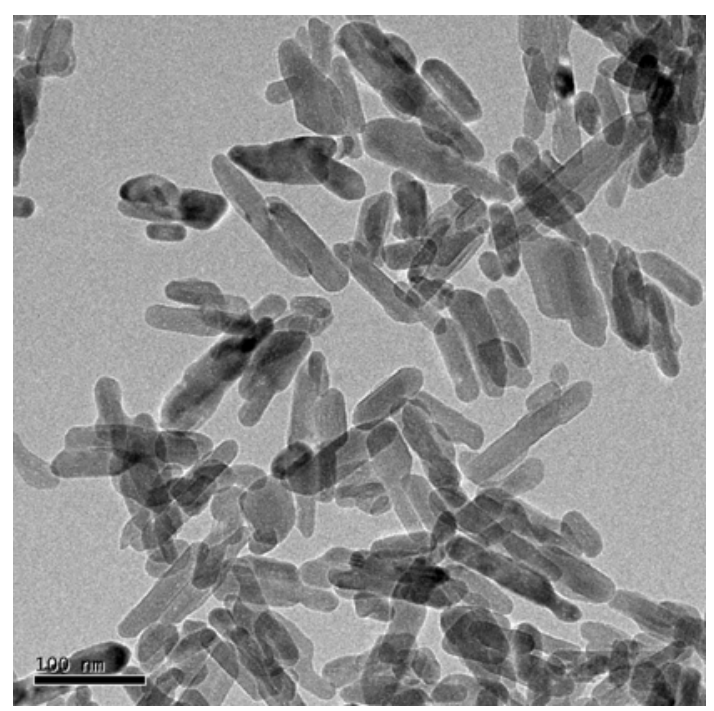


Sr-HAp

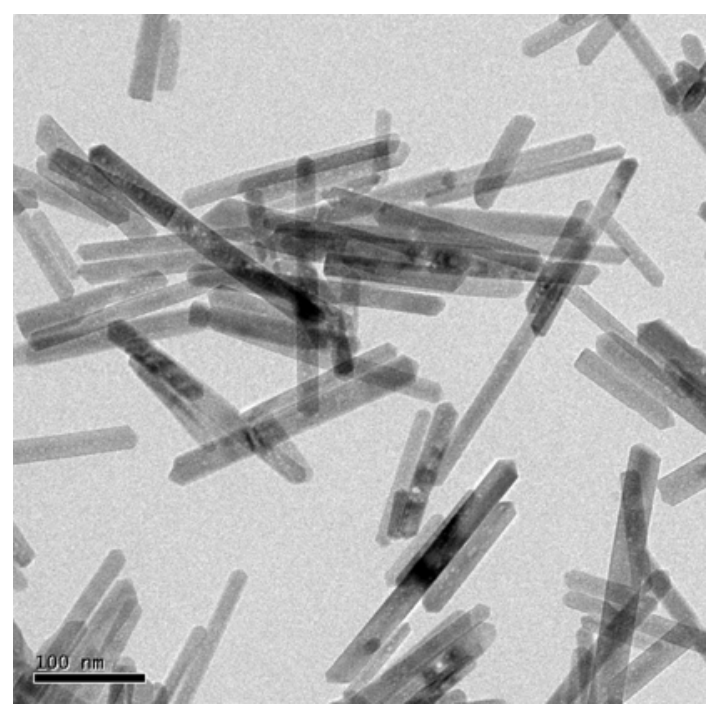




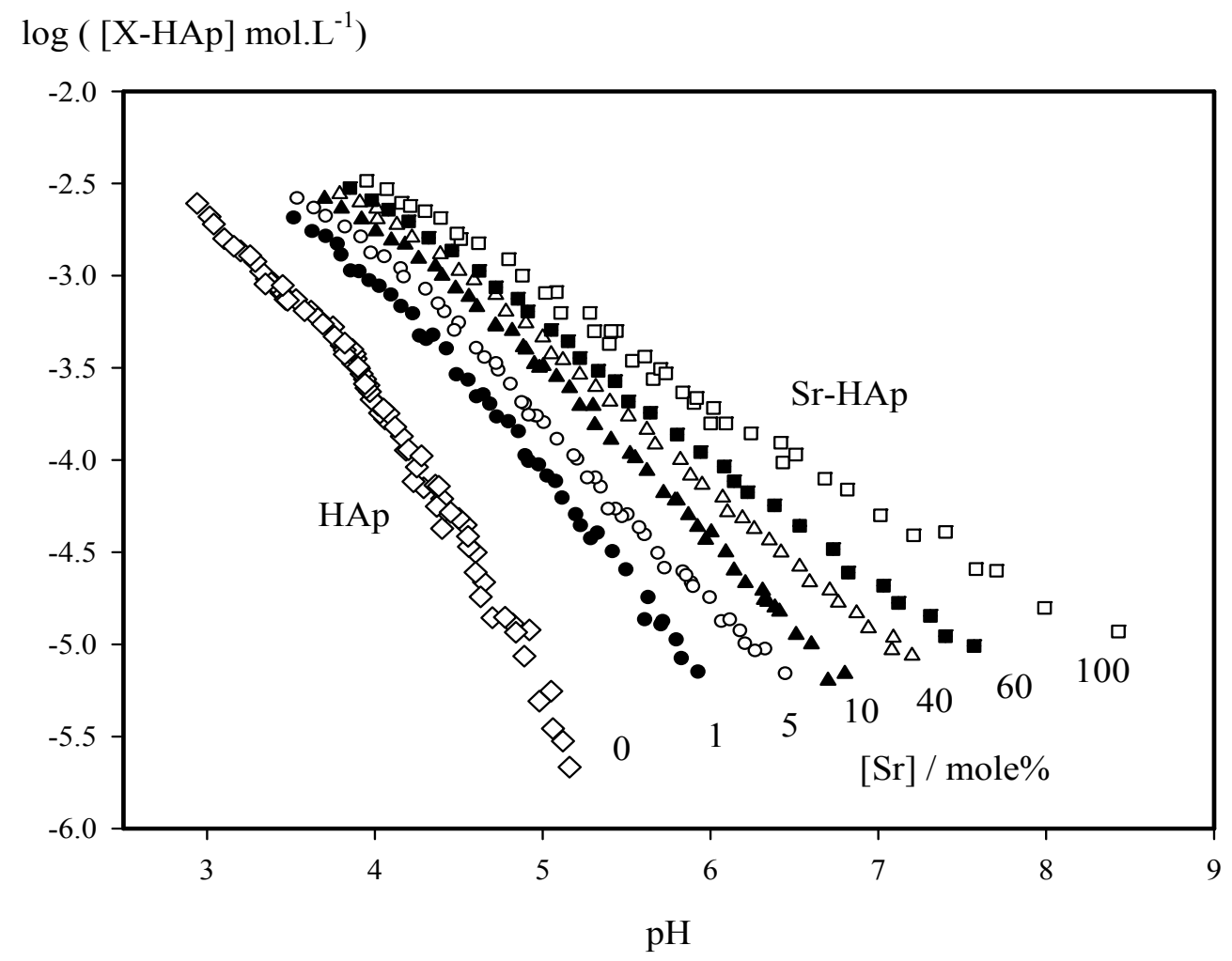




\section{Sr1-HAp}

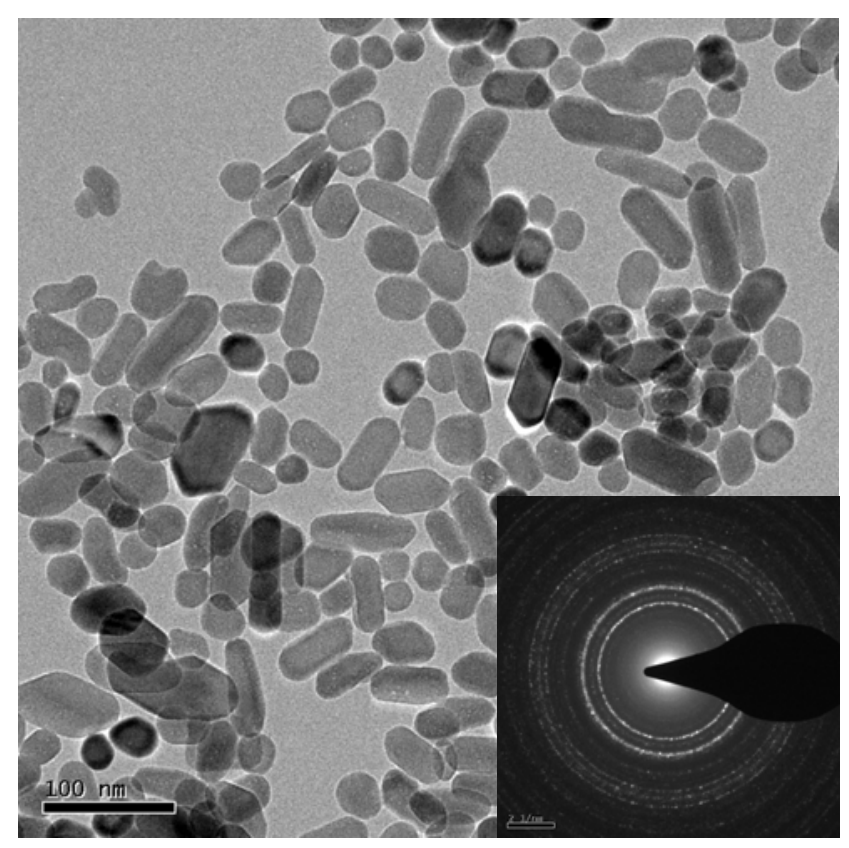

pH 3.59

\section{Sr5-HAp}

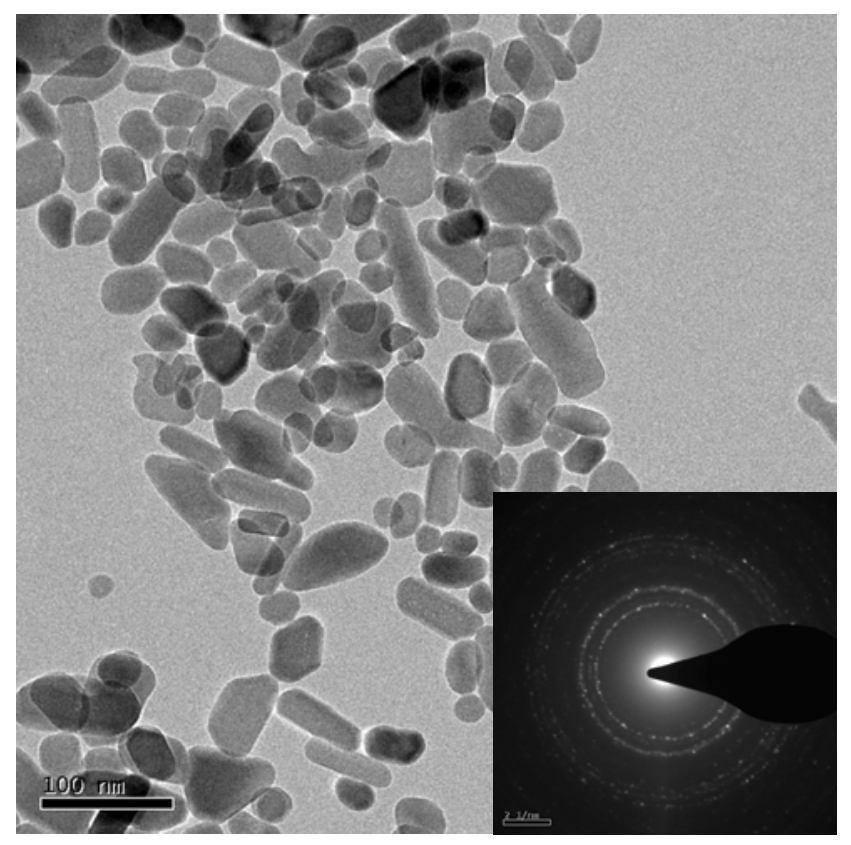

pH 4.88 


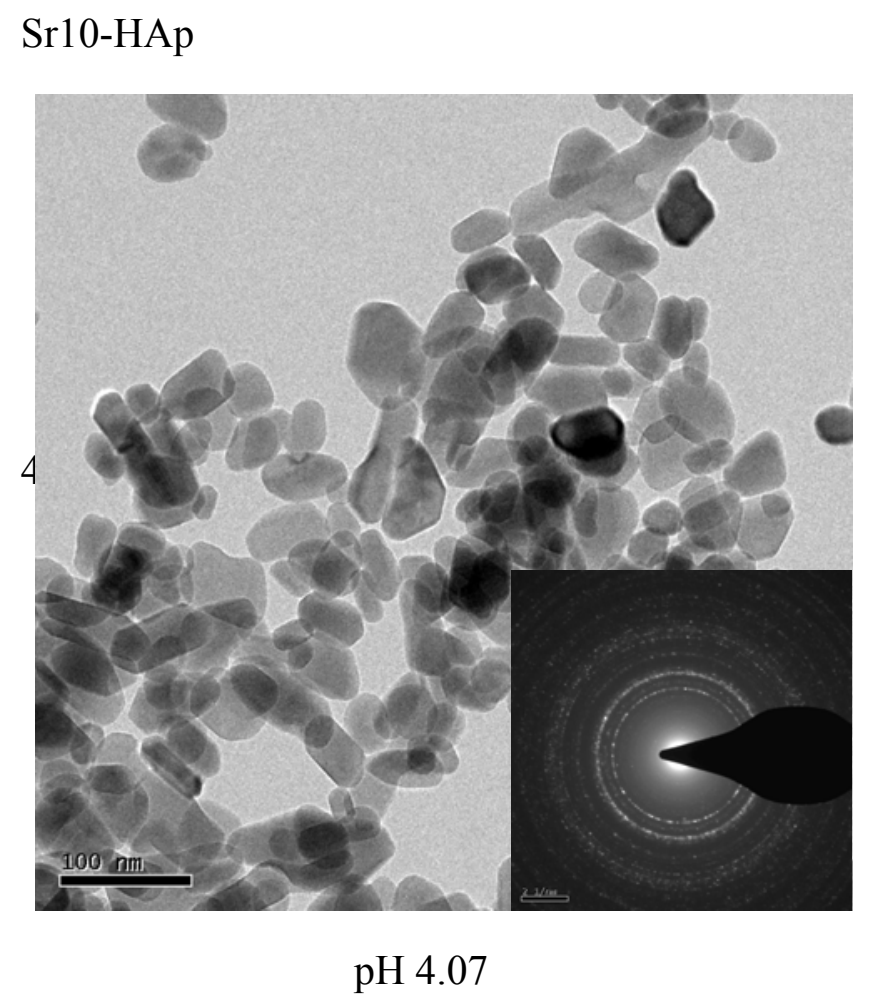

Sr40-HAp

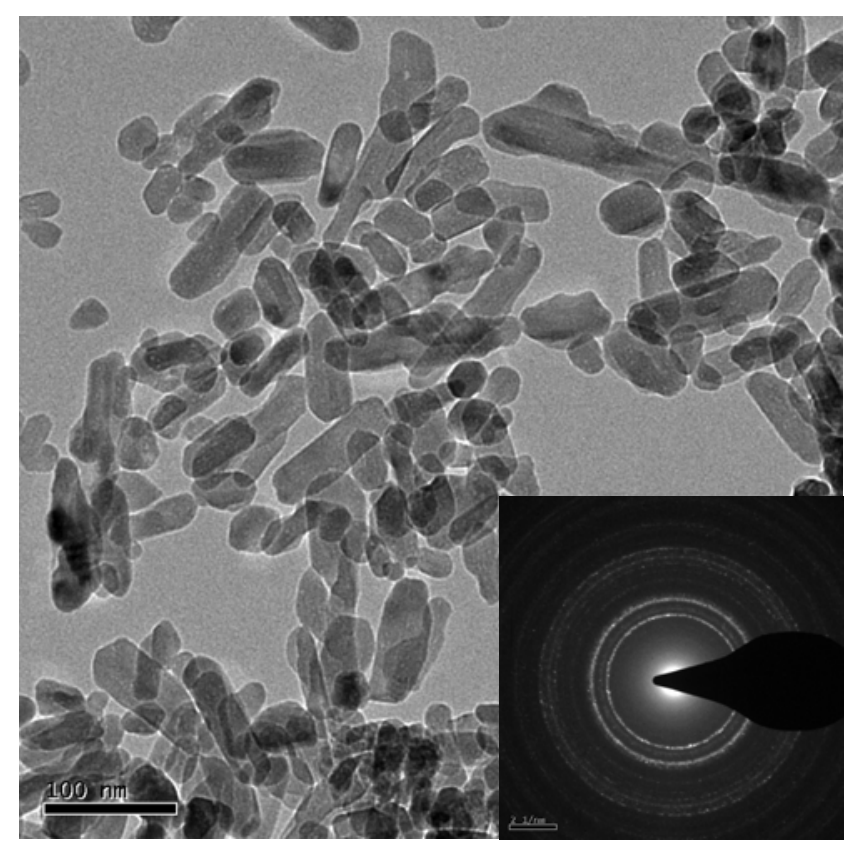

pH 4.06 
Sr60-HAp

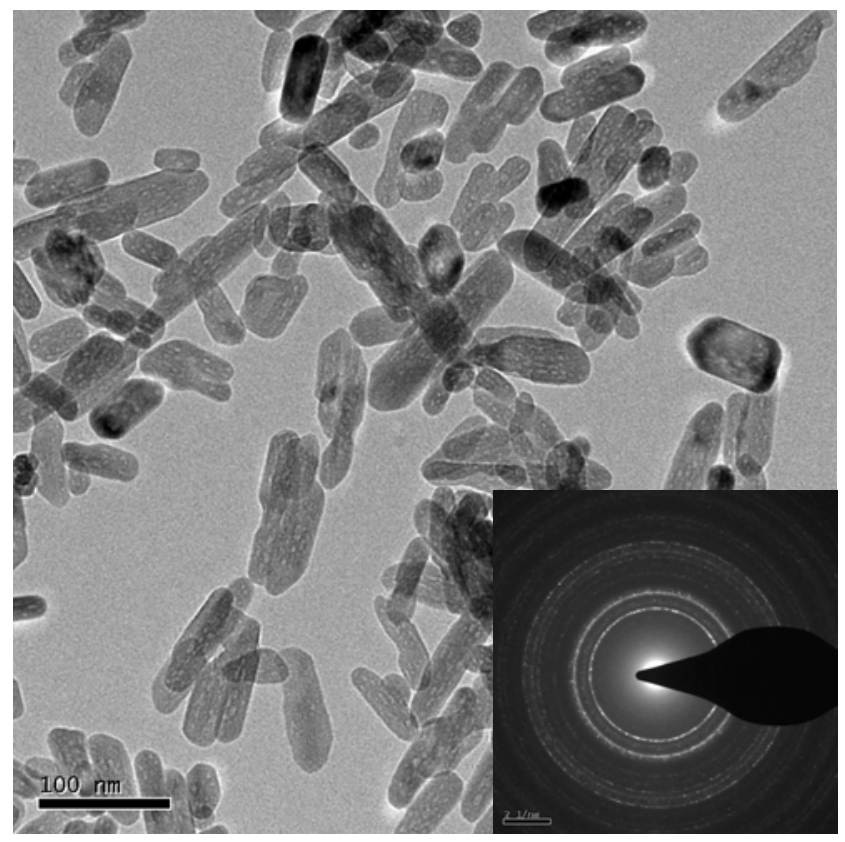

pH 4.11

Sr-HAp

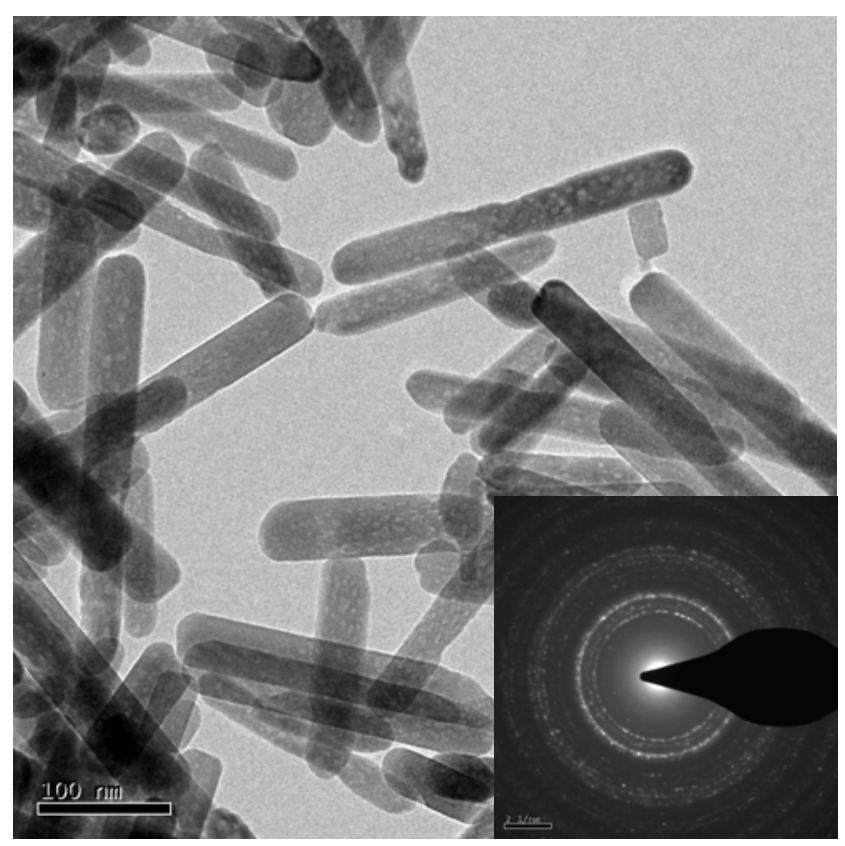

pH 4.27 
Pan et al.

Fig. 5

Sr10-HAp

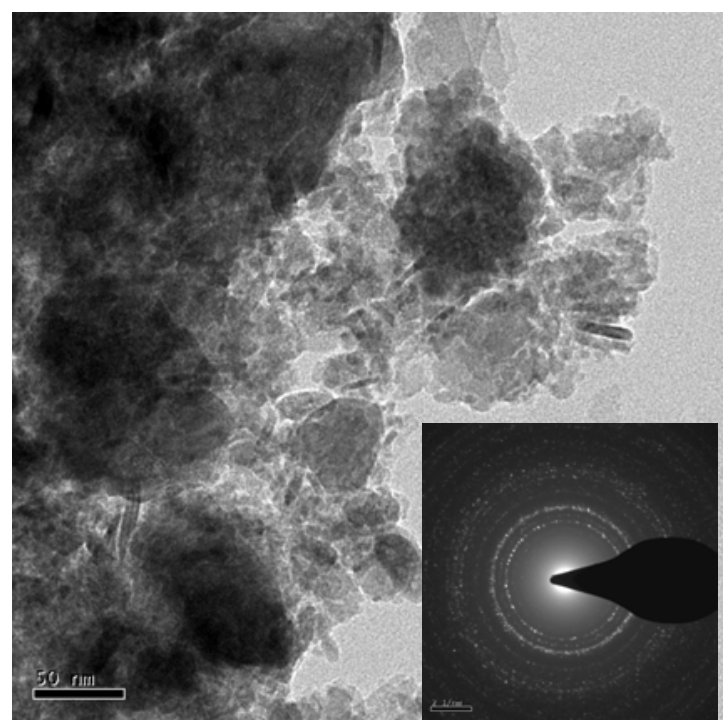

Sr-HAp

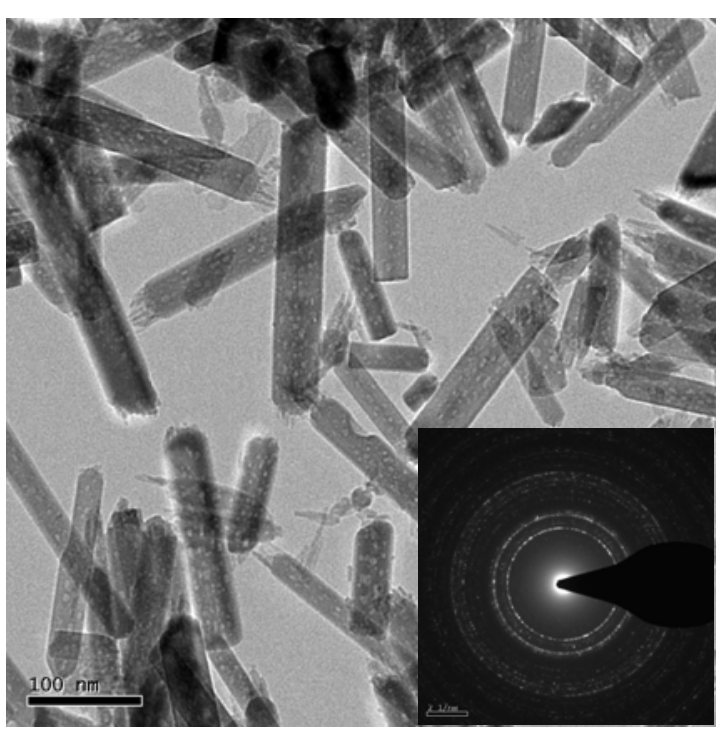


Pan et al.

Fig. 6

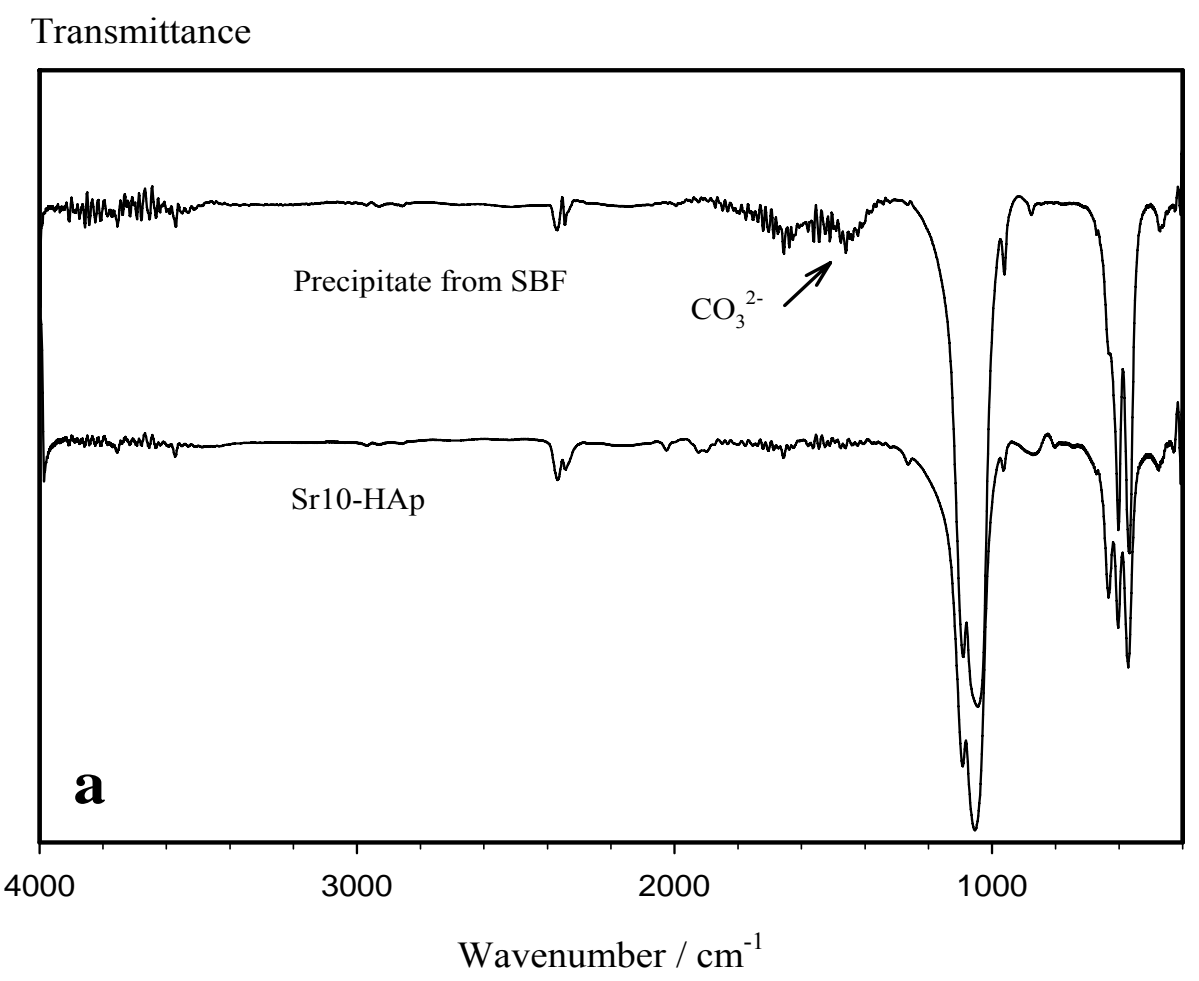

Transmittance

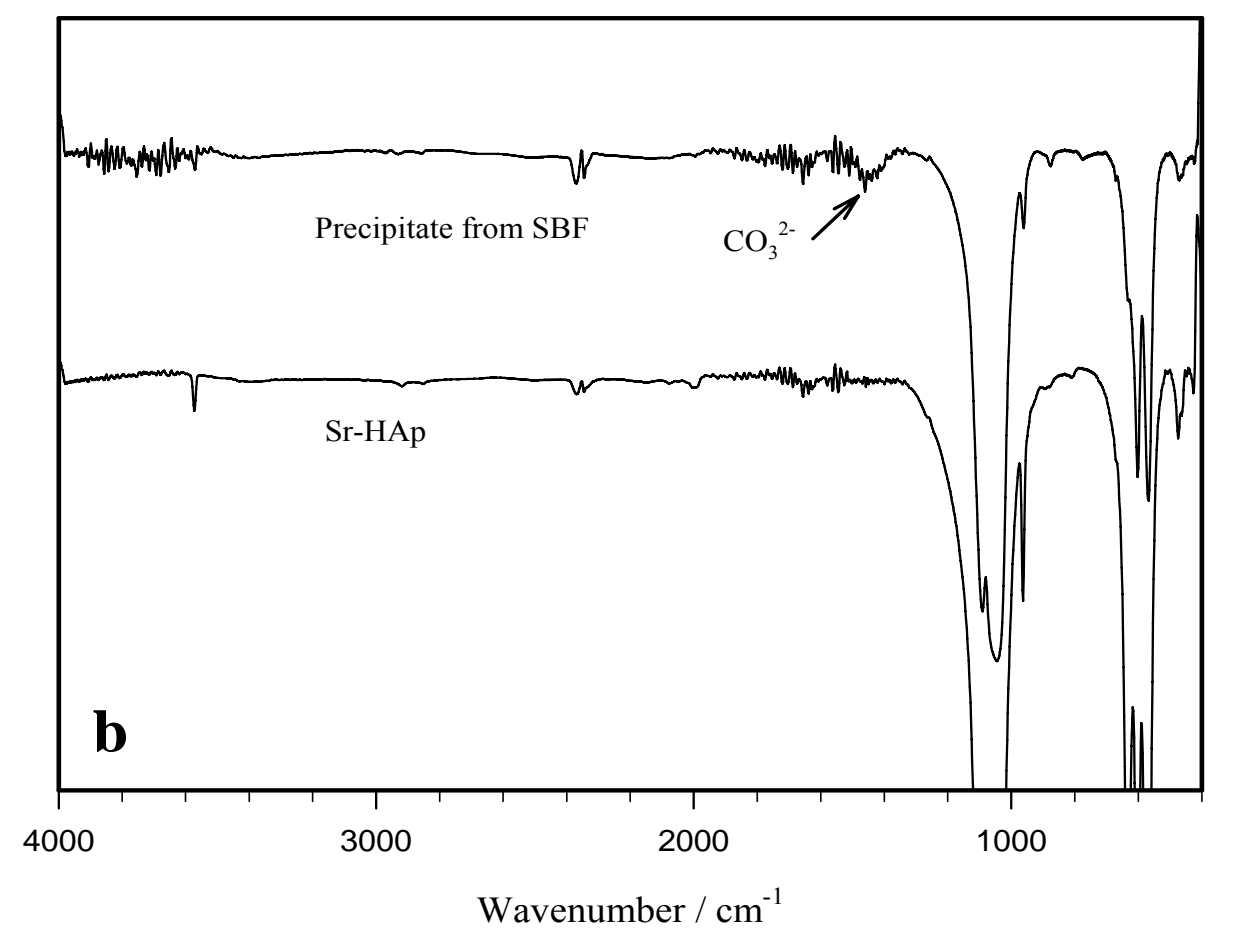


Pan et al.

Fig. 7

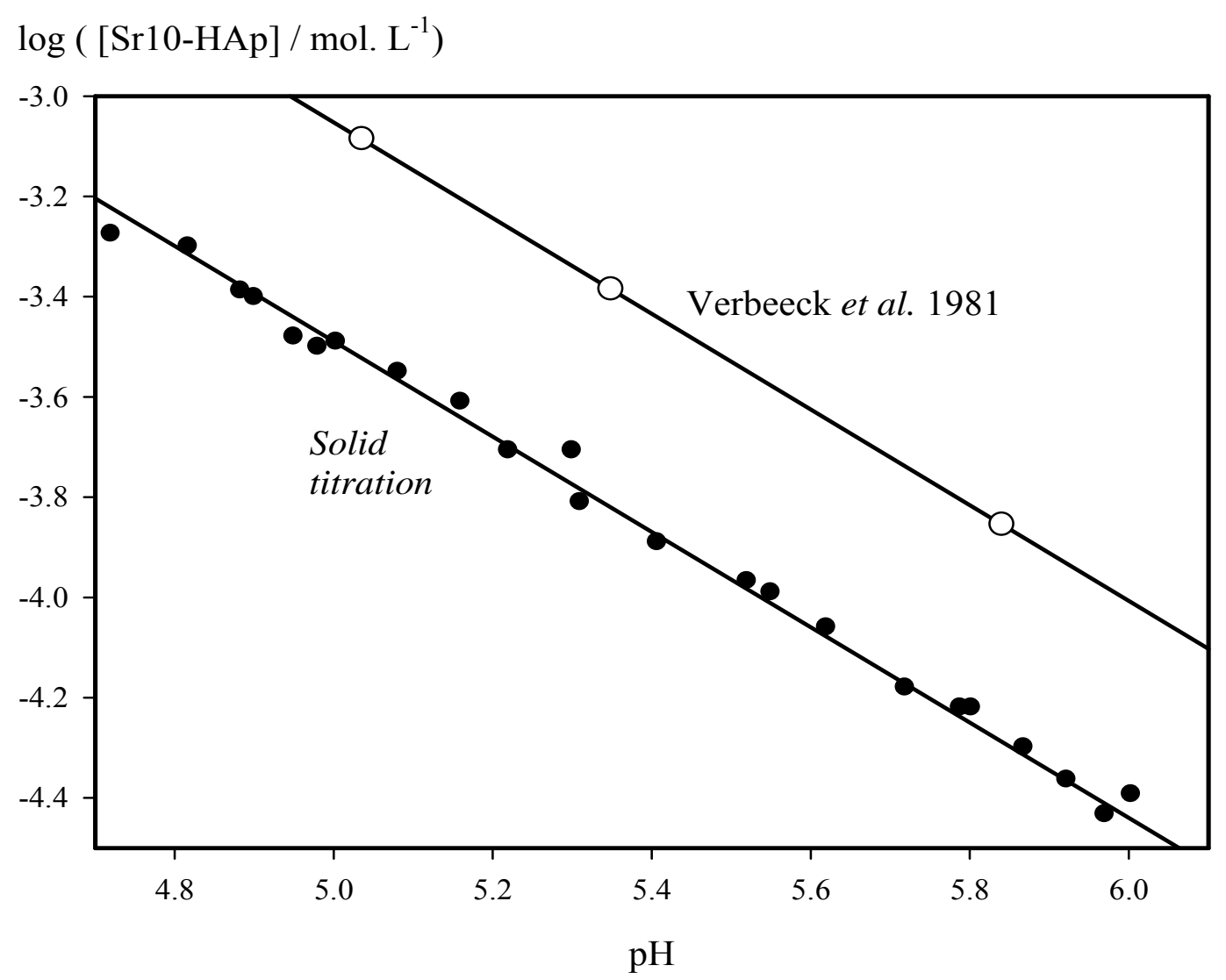

